\title{
The Acute Effects of High-Intensity Cycling Exercise on Arterial Stiffness in Adolescent Wrestlers
}

\author{
by \\ Okkes Alpaslan Gencay1, Murat Baykara², Adnan Demirel', Ejder Berk ${ }^{3}$, \\ Selcuk Gencay ${ }^{1}$
}

\begin{abstract}
The aim of this study was to determine the acute effects of high-intensity cycling exercise on the variables of carotid artery compliance, distensibility and beta stiffness index in elite adolescent wrestlers. The subjects were elite athletes competing in national, European and World Championships, who attended a training camp in the province of Kahramanmaras organized by the Turkish Centre for Olympic Preparation. The study sample comprised 31 male elite wrestlers with a mean age of $15.90 \pm 0.87$ years, body height of $165.97 \pm 9.7 \mathrm{~cm}$ and body mass of $66.3 \pm 18.45 \mathrm{~kg}$. The arterial stiffness variables of the wrestlers were measured with high-resolution Doppler ultrasonography before and 5 min after $30 \mathrm{~s}$ of high-intensity cycling exercise (the Wingate Anaerobic Cycling test). The results showed a statistically significant correlation between mean power performance and carotid artery compliance at the 5th min after a single cycling sprint exercise $(p<0.05)$. No correlation was determined between peak power and the arterial stiffness variables $(p>0.05)$. The study results indicate that acute changes in arterial stiffness variables are associated with the performance level of high-intensity cycling exercise in a group of elite adolescent wrestlers.
\end{abstract}

Key words: sprint performance, anaerobic exercise, arterial sclerosis.

Abbreviations: AC Arterial compliance, BP Blood pressure, CD Cross-sectional distensibility, DBP Diastolic blood pressure, DD Minimum carotid (diastolic) diameter, FI Fatigue index, MP Mean power, PP Peak power, SBP Systolic blood pressure, SD Maximum carotid (systolic) diameter, WAnT Wingate anaerobic test, $\beta$ Beta stiffness index

\section{Introduction}

Several studies have shown exercise to be related to advanced arterial stiffness (Okamoto and Masuhara, 2007; Schmidt-Trucksass et al., 2000). In reality there are many forms of exercise. The level of arterial stiffness has been shown to be low in individuals undertaking regular aerobic exercise compared to those not taking aerobic exercise (Okamoto and Masuhara, 2007). The pulse rate is defined by increased arterial stiffness or compliance, and this has an effect on the myocardial function capacity and coronary perfusion. In both conditions, an effect is seen in exercise capacity and cardiovascular risk (Kingwell et al., 2002).

High resistance strength training is related to large artery stiffness and higher pulse pressure has been shown in those undertaking this type of exercise compared to a control group (Kingwell et al., 2002). Acute high-intensity cycling exercise is known to increase carotid artery stiffness, reduce carotid artery diameter and increase carotid artery blood pressure pulsatility and blood flow pulsatility (Babcock et al., 2017).

It is important to understand how acute high-intensity exercise affects not only arterial

\footnotetext{
1 - Department of Physical Education and Sport Teaching, School of Physical Education and Sports, Kahramanmaras Sutcu Imam University, Kahramanmaras, Turkey.

2 - Departmanet of Radiology, Faculty of Medicine, Kahramanmaras Sutcu Imam University, Kahramanmaras, Turkey.

3 - Department of Physical Medicine and Rehabilitation, Faculty of Medicine, Kahramanmaras Sutcu Imam University, Kahramanmaras, Turkey.
}

Authors submitted their contribution to the article to the editorial board.

Accepted for printing in the Journal of Human Kinetics vol. 69/2019 in September 2019. 
stiffness, but also the link between central BP and central arterial stiffness (Rossow et al., 2010). One explanation is that acute maximal exercise can induce substantial changes in arterial stiffness (Bunsawat et al., 2017) and may reveal vascular abnormalities, not apparent at rest (Shim et al., 2011; Yan et al., 2014). During exercise, parasympathetic activity is decreased while sympathetic activity is increased (White and Raven, 2014). Such a response is likely driven by the transient increase in sympathetic nerve activation following such high-intensity exercise (Stuckey et al., 2012). Increases in sympathetic nerve activity have been associated with central arterial stiffening (Hart et al., 2013; Smith and Minson, 2012). Such mechanisms imply that the reflex baroreceptor action and reflex neuronal feedback are provoked by muscle contraction (Michelini and Stern, 2009).

High-intensity acute sprint exercises show a similar hemodynamic reaction as resistance exercises (Sagiv et al., 1999). It is important to understand not only the effects of high-intensity, dynamic, acute cycling exercise on arterial stiffness, but also the relationship with the anaerobic performance of adolescent elite wrestlers.

In the same way as acute resistance exercises, high-intensity cycling exercises increase short-term arterial stiffness (Rakobowchuk et al., 2009; Rossow et al., 2010). With stiffening of the arterial walls together with increased systolic pressure and reduced diastolic pressure, high pulse pressure (PP) occurs. In healthy individuals, large arteries reduce the amplitude of undulations in the flow and pressure and provide compatibility. If arterial elasticity is lost, the capability to ameliorate excessive passage of hemodynamic pulsatility to target organs is reduced (Mitchell et al., 2011). Researchers have determined that wall stress is a potential factor of increased arterial stiffness in elite athletes training intensively (Kasikcioglu et al., 2004).

In previous studies, only cardiovascular responses of younger males to an acute period of resistance training have been researched. It appears that whole body resistance exercise creates an acute increase in arterial stiffness in young adults (Thiebaud et al., 2016).

As yet, central BP response to highintensity sprint exercise has not been clarified and it is also not known if this response is related to changes in central arterial stiffness after this type of exercise (Rossow et al., 2010). Very few studies have been conducted to examine the effects of submaximal anaerobic exercise on arterial stiffness (Rossow et al., 2010; Yoon et al., 2010).

Therefore, the aim of this study was to determine the effects of a supramaximal cycling sprint (Wingate Anaerobic Test) on arterial compliance (AC), cross-sectional distensibility (CD) and beta stiffness index ( $\beta$ ) in adolescent wrestlers. It was hypothesized that a bout of highintensity exercise would result in acute increases of artery stiffness. The second hypothesis of the study was that increasing high-intensity exercise performance would result in a significant decrease in carotid artery stiffness.

\section{Methods}

\section{Subject Characteristics}

The study included 31 elite national wrestlers with a mean age of $15.9 \pm .87$ years, body height of $165.97 \pm 9.7 \mathrm{~cm}$, and body mass of $66.3 \pm$ $18.45 \mathrm{~kg}$. The wrestlers and their parents gave written informed consent to participate in the study. Approval for the study was granted by the Local Ethics Committee for Non-invasive Clinical Research of the Kahramanmaras Sutcu Imam University Medical Faculty (reference number: 07.27.2016/02). All procedures were applied in compliance with the Declaration of Helsinki (revision 2008).

Study Design

Subjects were instructed to refrain from strenuous exercise for $12 \mathrm{hrs}$ prior to testing and any beverage including caffeine for $24 \mathrm{hrs}$ prior to testing. All subjects were at least $2 \mathrm{hrs}$ postprandial at the time of testing.

Carotid Diameter Measurements and Calculations

To quantitatively evaluate the changes in arterial stiffness and distensibility before and after exercise, measurements were taken with ultrasonography and sphygmomanometer, respectively. Data acquired prior to exercise constituted the baseline reference and measurements taken after exercise reflected the relative changes. The carotid arteries were evaluated using high-resolution Doppler ultrasonography (Aplio ${ }^{\mathrm{TM}} 400$ Platinum, Toshiba Medical Systems Corporation, Tochigi, Japan) with a broadband linear probe (PLT-704SBT ${ }^{\circledR}$ ). 
The probe was placed at a point $2 \mathrm{~cm}$ prior to the bifurcation of the right carotid artery. The measurements included intima-media thickness (IMT) and lumen diameters (DD and SD of each artery during the end-diastolic and end-systolic phases of the cardiac cycle. At the same time, the pulse rate and pressures (systolic pressure, diastolic pressure) were measured using an automatic sphygmomanometer (OCR Vitagnost 2015, MARS ${ }^{\circledR}$, Taiwan) on the left arm.

The ultrasonography

and sphygmomanometer measurements were collated to calculate the quantitative variables reflecting arterial stiffness (Baykara et al., 2012, 2017).

Arterial compliance (AC) $=\pi\left(\mathrm{DD}^{2}-\mathrm{SD}^{2}\right) /$ 4(SBP - DBP)

Cross-sectional distensibility $(\mathrm{CD})=\mathrm{SD}^{2}-\mathrm{DD}^{2} /$ $\mathrm{DD}^{2}$ (SBP - DBP)

Beta stiffness index $(\beta)=1 \mathrm{n}(\mathrm{SBP} / \mathrm{DBP}) /$ [(SD - DD)/DD] (Oliver and Webb, 2003).

DD: Diastolic (or minimum) arterial diameter, SD: Systolic (or maximum) arterial diameter, DBP: Lowest (diastolic) carotid pressures, SBP: Highest (systolic) carotid pressure.

\section{Wingate Anaerobic Test (WAnT)}

All the study participants were instructed not to engage in strenuous activity for $24 \mathrm{hrs}$ before the exercise test. Using a mechanically braked cycle ergometer (894 E, Monark ${ }^{\circledR}$ ), the WAnT was performed according to the widely accepted recommendations for standardization (Inbar et al., 1996). A 3-5-minute warm-up on the cycle ergometer was permitted for each subject to achieve a heart rate of $130-140$ beats per minutes (bpm). After a $10 \mathrm{~min}$ rest the subjects were then instructed to pedal as fast as possible. The resistance load was set at $7.5 \%$ of the subject's body mass.

Verbal encouragement was given for the subjects to maintain as high a rate of pedalling as possible throughout the $30 \mathrm{~s}$ duration of the test. Using standard software, peak power, mean power and the fatigue index were calculated for each subject. A Polar ${ }^{\circledR}$ V800 heart rate monitor transmitter was placed on the chest of each subject for the monitoring of the heart rate during the warm-up, the 30-s test, and the 5-min recovery period. The data were processed with a running average of $0.5 \mathrm{~s}$. Peak power (PP) was defined as the highest value of Watts (W) during $30 \mathrm{~s}$ of the test, and mean power (MP) was calculated as the average of all values during $30 \mathrm{~s}$ of the test. The difference between PP and the lowest value at the end was calculated relative to PP and used as the fatigue index (\%) (FI).

\section{Anthropometric measurements}

Standing height and body mass measurements were taken with the participants wearing light-weight clothing and no shoes. Using a Seca ${ }^{\circledR}$ (Model 764) stadiometer, measurements were recorded to the nearest $0.5 \mathrm{~cm}$ for body height, and $0.1 \mathrm{~kg}$ for body mass.

\section{Statistical Analysis}

Data analyses were applied using IBM $^{\oplus}$ SPSS (version 22.0 for Windows) software. Conformity to normal distribution of variables was assessed with the Shapiro-Wilk test and qualitatively using histograms and Q-Q plots. Data were expressed as mean \pm standard deviation. The significance of the change in arterial stiffness variables before and $5 \mathrm{~min}$ after the WAnT was evaluated with the paired samples t-test. Univariate correlations were analyzed with Pearson $r$ correlation coefficients. A value of $p<$ 0.05 was accepted as statistically significant.

\section{Results}

The demographic data of the elite adolescent wrestlers included in the study and the WAnT performance variables are presented in Table 1. The comparisons of blood pressure values, common carotid artery dimensions and carotid wave intensity analysis at before and $5 \mathrm{~min}$ after the WAnT are presented in Table 2. Statistically significant increases were determined in brachial systolic, diastolic blood pressures, as well as intima media thickness values $(p<0.05)$. Five minutes after the WAnT, a statistically significant decrease was determined in maximum carotid (systolic) diameter, arterial compliance $(A C)$, and beta stiffness index $(p<0.05)$.

Univariate correlations

Pearson correlations were computed to examine the relationship of the variables and the results are shown in Table 3. A positive correlation was determined between post-WAnT mean power for both $\mathrm{AC}_{\text {post }} r=0.5$, and $\beta_{\text {post }} r=0.36,(p<0.05)$, which would be considered a low to moderate effect size according to Cohen (Cohen, 1988). This means that a wrestler with relatively high mean power was very likely to have high $\mathrm{AC}_{\text {post, }}$ and high $\beta_{\text {post }}$ (Figure 1). 
Table 1

\begin{tabular}{ll}
\multicolumn{2}{c}{ Participants' demographics $(N=31)$} \\
\hline Variables & Mean $\pm S D$ \\
\hline Age (years) & $15.9 \pm 0.87$ \\
Body height $(\mathrm{cm})$ & $165.97 \pm 9.7$ \\
Body mass $(\mathrm{kg})$ & $66.3 \pm 18.45$ \\
Body mass index $\left(\left(\mathrm{kg} / \mathrm{m}^{2}\right)\right.$ & $23.65 \pm 4.19$ \\
Peak power $(\mathrm{W})$ & $722.23 \pm 298.3$ \\
Mean power $(\mathrm{W})$ & $520.05 \pm 165.52$ \\
Fatigue Index $(\%)$ & $59.92 \pm 16.38$ \\
\hline
\end{tabular}

Data presented as mean $\pm S D$

Table 2

Blood pressure and carotid diameter values before and after the Wingate test $(N=31)$

\begin{tabular}{llll}
\hline Variables & Baseline & Post & Paired $t$ test, $p$ value \\
\hline SBP $(\mathrm{mmHg})$ & $118.71 \pm 12.56$ & $147.77 \pm 17.79$ & $t_{(30)}=-8.528, p=0.00^{\mathrm{a}}$ \\
DBP $(\mathrm{mmHg})$ & $71.48 \pm 8.571$ & $76.81 \pm 16.93$ & $t_{(30)}=-1.784, p=0.08$ \\
DD $(\mathrm{mm})$ & $6.27 \pm 0.86$ & $6.25 \pm 1.07$ & $t(30)=0.152, p=0.88$ \\
SD $(\mathrm{mm})$ & $5.1 \pm 0.78$ & $4.7 \pm 0.77$ & $t_{(30)}=3.543, p=0.00^{\mathrm{a}}$ \\
CD & $0.012 \pm 0.005$ & $0.011 \pm 0.004$ & $t(30)=0.347, p=0.73$ \\
AC & $0.24 \pm 0.1$ & $0.19 \pm 0.07$ & $t(30)=2.846, p=0.008^{\mathrm{a}}$ \\
$\beta$ & $5.17 \pm 1.37$ & $3.85 \pm 1.27$ & $t(30)=4.72, p=0.00^{\mathrm{a}}$ \\
\hline
\end{tabular}

Values are mean $\pm S D$

$\$ B P$ systolic blood pressure, DBP diastolic blood pressure, DD minimum carotid (diastolic) diameter, SD maximum carotid (systolic) diameter, CD cross-sectional distensibility, $A C$ arterial compliance, $\beta$ beta stiffness index, ${ }^{a} p<0.05$

Table 3

Intercorrelations for WAnT performances and predictor variables $(N=31)$

\begin{tabular}{llllllllll}
\hline & 1 & 2 & 3 & 4 & 5 & 6 & 7 & 8 & 9 \\
\hline 1. PP $(\mathrm{W})$ & - & $.9^{\mathrm{b}}$ & $.49^{\mathrm{b}}$ & .08 & .33 & -.28 & -.13 & .33 & -.15 \\
2. $\mathrm{MP}(\mathrm{W})$ & & - & $.37^{\mathrm{a}}$ & .22 & $.5^{\mathrm{b}}$ & -.2 & .01 & .13 & $-.36^{\mathrm{a}}$ \\
3. FI $(\%)$ & & & - & .13 & .23 & .03 & -.25 & .19 & .07 \\
4. ACbefore & & & & - & $.53^{\mathrm{b}}$ & $.69^{\mathrm{b}}$ & .118 & $-.36^{\mathrm{a}}$ & -.2 \\
5. AC post & & & & & - & .04 & $.52^{\mathrm{b}}$ & .00 & $-.51^{\mathrm{b}}$ \\
6. CD before & & & & & & - & .03 & $-.73^{\mathrm{b}}$ & -.06 \\
7. CD post & & & & & & & - & -.2 & $-.77^{\mathrm{b}}$ \\
8. $\beta$ before & & & & & & & & - & .31 \\
9. $\beta_{\text {post }}$ & & & & & & & - \\
\hline
\end{tabular}

${ }^{a}$ Univariate correlation $(p<0.05),{ }^{b}$ Univariate correlation $(p<0.01)$. 

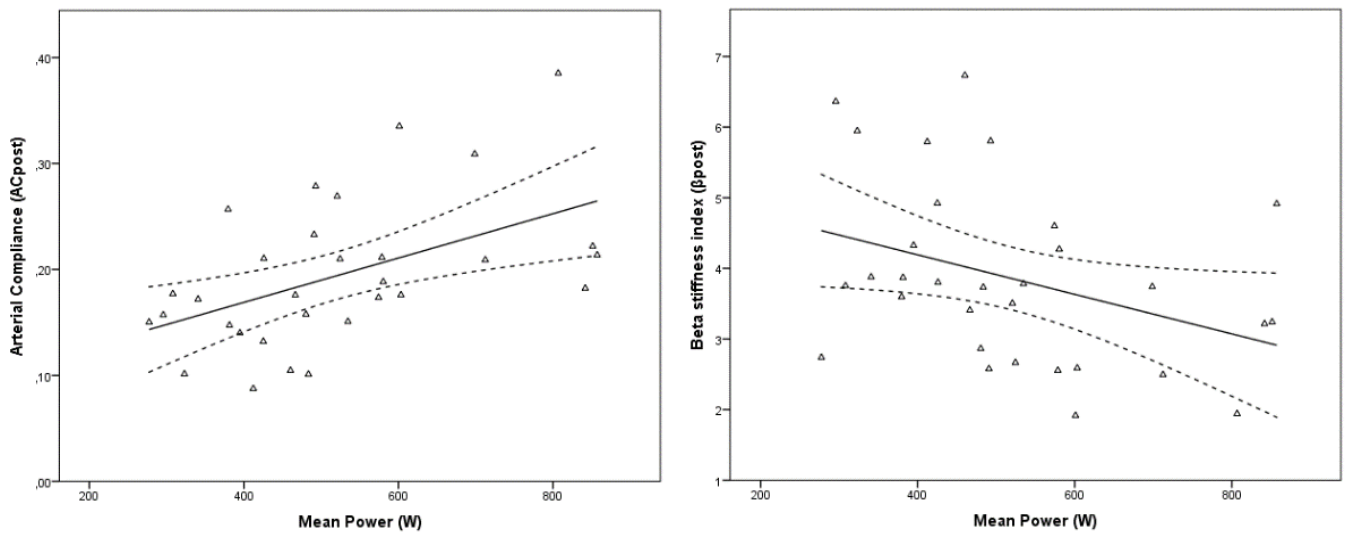

Figure 1

Scatterplot showing a curvilinear relationship between mean power and $A C_{\text {post, }} \beta_{\text {post }}$ results.

No statistically significant relationship was determined post-WAnT for both peak power and the fatigue index with arterial stiffness variables $(p>0.05)$.

\section{Discussion}

The major findings of this study were as follows: a single bout of 30-s high-intensity cycling exercise resulted in (a) a decrease in systolic diameter at the 5th min after the 30-s Wingate test $(\mathrm{p}<0.05)$ and diastolic diameter also decreased, but not to a statistically significant level, (b) there was a statistically significant decrease in arterial compliance and the beta stiffness index at the 5th min of recovery following the 30-s cycling exercise, and (c) the subjects with relatively high mean power had lower arterial stiffness, and beta stiffness index values.

The decrease in arterial compliance and the increase in stiffness determined in this study support the first hypothesis. There was a change in arterial stiffness according to the performances in the 30-s high-intensity anaerobic cycling exercise. The subjects with a high mean power level showed an increase in arterial compliance and a decrease in stiffness. This finding supports the second hypothesis of the study. These findings are consistent with those of Rossow et al. (2010).
These results suggest that changes in arterial stiffness variables affect anaerobic peak power and the mean power performance level in

particular in elite adolescent wrestlers. Previous studies have reported an increase in arterial stiffness following both high-intensity dynamic and static exercises (Edwards et al., 2008; Sharman et al., 2005). The change in arterial compliance following supramaximal exercise originates from the change in distension pressure. A similar change seen in the beta stiffness index supports this finding. Although no change was seen in the beta stiffness index in a study by Rossow et al. (2010), the reduction in the present study is of importance. The difference between the results of these two studies could be due to the sample of the current study being younger, high performance athletes.

It has been shown that those who engage in regular, high-intensity resistance training (HIT) have lower levels of carotid arterial compliance than a sedentary age-matched control group in young and middle-aged populations (CortezCooper et al., 2005; Miyachi et al., 2003). In subjects of younger age, moderate aerobic training, but not high-resistance strength training, has been shown to reduce large artery stiffness, although older subjects seem to be resistant to such adaptation due 
to established isolated systolic hypertension (Kawano et al., 2006; Kingwell et al., 2002). A crosssectional study also found that young males who performed regular resistance training had lower levels of systemic arterial compliance than their sedentary peers (Bertovic et al., 1999).

Previous studies have shown a relationship between high-resistance strength training and stiffer large arteries and higher pulse pressure compared to a matched control group (Kingwell et al., 2002; Miyachi et al., 2003). The balance of myocardial blood supply and demand is regulated to a large extent by large artery stiffness, and this has serious implications for athletic performance and for the ischaemic threshold in coronary disease patients (CortezCooper et al., 2005; Kingwell et al., 2002).

The results of this study showed that the vascular response to acute, high-intensity sprint exercise was similar to the response to acute resistance exercise and this is consistent with the finding of previous studies (Rakobowchuk et al., 2009; Tordi et al., 2010). Relative upper body muscular strength has been inversely associated with central arterial stiffness (Fahs et al., 2010). Müller et al. (2015) demonstrated that running at either moderate or vigorous intensity causes an increase in arterial stiffness in middle- and longdistance runners. Kawano et al. (2006) also reported that moderate intensity resistance exercises increased arterial stiffness. Therefore, the severity of resistance training must be adjusted on an individual-specific basis.

Another reason which has been proposed for the increase in arterial stiffness is the type of resistance training, but the effects on upper and lower extremities have not yet been clarified (Maeda et al., 2006). High-intensity resistance exercises are known to strongly stimulate the expression of norepinephrine (Raastad et al., 2001), and in this effect vasoconstriction can be intensified due to a sympathetic adrenergic vasoconstrictor effect. Although the underlying mechanisms of arterial stiffness caused by exercise have not been fully explained, it has been considered that arterial stiffness could contribute to a sympathetic adrenergic vasoconstrictor tone response (Okamoto et al., 2009).

The finding of arterial stiffness immediately after resistance exercise could be explained by the Valsalva maneuver during resistance exercise. The Valsalva maneuver is commonly utilized during high-intensity or maximum-intensity resistance exercise (Yoon et al., 2010). Differences in carotid baroreceptor sensitivity may also play a role in increased arterial stiffness following resistance exercise (Heffernan et al., 2007). In a study by Eller (2007), significant inverse correlations were determined between increased catecholamine levels, increased arterial stiffness, and cardiac regulation of the vagus nerve, thereby demonstrating that resistance exercise can activate the sympathetic nervous system.

Systolic and pulse pressure values are lower in the aorta than in the upper and lower extremities where there are varying degrees of amplification depending on elasticity and localisation (Mitchell et al., 2011). Rowell et al. (1968) demonstrated that central systolic pressure can vary from peripheral systolic pressure by up to $80 \mathrm{mmHg}$ during maximal exercise. Very little attention had been paid to this disparity until a recent study confirmed that during cycling exercise, which only involved the lower body, peripheral systolic pressure overestimated the actual pressure load of the heart (Sharman et al., 2005).

It has been shown that a single short session of high-intensity cycling exercise increases carotid artery stiffness, carotid pressure pulsatility and carotid blood flow pulsatility and causes acute constriction of the common carotid artery (Babcock et al., 2017). Although the anaerobic test is a dynamic form of exercise, the blood pressure responses have been seen to be similar to the responses to isometric exercise (Sagiv et al., 1999). Significant increases in carotid artery stiffness following HIT were also seen in the current study, which was consistent with previous findings (Babcock et al., 2015; Rakobowchuk et al., 2009; Rossow et al., 2010). In a study by Hou et al. (2013) leg anaerobic exercises were shown to increase arterial stiffness and modulate some hemodynamic variables to a significant degree.

In contrast to the findings of previous studies, it was determined in the current study of highly conditioned adolescent wrestlers that the vascular walls showed a different kind of reaction in high-intensity anaerobic exercise. Miyachi et al. (2003) indicated that chronic resistance training in middle-aged males was associated with lower rather than higher central arterial compliance. In 
addition, age-related reductions in arterial compliance appear to be greater in males who perform resistance training compared to those who are sedentary. There is a further relationship to LV concentric hypertrophy of the lower arterial compliance observed in resistance-trained males, which has been presumed to occur through vascular-ventricular coupling.

In the elite adolescent wrestlers of the current study, there was a strong inverse association between resting carotid compliance and the changes in compliance. Therefore, for athletes engaged in anaerobic sports, high intensity exercise should be undertaken with caution. Although the increases in blood pressure and arterial stiffness caused by resistance training can be decreased with subsequent aerobic exercise, when the aerobic exercise is performed before resistance exercise, the same positive effects may not occur (Okamoto and Masuhara, 2007).

\section{Limitations of this study}

There are several limitations of this study. The anaerobic performance of wrestlers could have been realized with tests more specific to wrestling performance than the lower body Wingate Anaerobic Cycling test. This study included only young male wrestlers, so the results may not be directly applicable to females or adult wrestlers. Future research should be conducted on the arterial stiffness of female and adult wrestlers and the use of "anaerobic power tests" specific for wrestling could be considered.

\section{Conclusions}

Blood pressure response to the acute period of high-intensity sprint exercise has not been clarified and it is also not known if this response is related to changes in arterial stiffness after this type of exercise. The current study focuses on the effects of a bout of high-intensity exercise on artery stiffness in adolescent elite wrestlers.

In conclusion, the findings of the present study showed that although arterial function was negatively affected by acute anaerobic exercise, this effect showed a difference related to the level of performance of the athlete. As the performance level increased, the effect decreased. The results of this study also showed that high-intensity cycling exercise caused a decrease of arterial compliance, yet athletes with a high performance level were less affected by this decrease.

It is important not only to understand how acute high-intensity dynamic cycling exercise affects arterial stiffness, but also the relationship with the anaerobic performance level of elite adolescent wrestlers. There is a need for further studies to examine the effects of acute and longterm high intensity exercise programs on arterial stiffness in elite wrestlers.

\section{Acknowledgements}

The authors thank all study participants for their understanding and willingness to participate.

\section{References}

Babcock MC, Lefferts WK, Heffernan KS. Relation between exercise central haemodynamic response and resting cardiac structure and function in young healthy men. Clin Physiol Funct Imaging, 2017; 37(4): 372378

Babcock MC, Lefferts WK, Hughes WE, Fitzgerald KL, Leyer BK, Redmond JG, Heffernan KS. Acute effect of high-intensity cycling exercise on carotid artery hemodynamic pulsatility. Eur J Appl Physiol, 2015; 115(5): 1037-1045

Baykara M, Demirel A, Yavuzatmaca İ, Bilgen M. Response of arterial Stiffness four weeks after terminating short-term aerobic exercise training in a sedentary lifestyle. J Ultrasound Med, 2017; 36(2): 353-359

Baykara M, Ozturk C, Elbuken F. The relationship between bone mineral density and arterial stiffness in women. Diagn Interv Radiol, 2012; 18: 441-445

Bertovic DA, Waddell TK, Gatzka CD, Cameron JD, Dart AM, Kingwell BA. Muscular strength training is associated with low arterial compliance and high pulse pressure. Hypertension, 1999; 33: 1385-1391 
Bunsawat K, Ranadive SM, Lane-Cordova AD, Yan H, Kappus RM, Fernhall B, Baynard T. The effect of acute maximal exercise on postexercise hemodynamics and central arterial stiffness in obese and normalweight individuals. Physiol Rep, 2017; 5(7): 1-9

Cohen J. Statistical power analysis for the behavioral sciences (2nd ed.). Hillsdale, NJ: Lawrence Erlbaum Associates; 1988

Cortez-Cooper MY, DeVan AE, Anton MM, Farrar RP, Beckwith KA, Todd JS, Tanaka H. Effects of high intensity resistance training on arterial stiffness and wave reflection in women. Am J Hypertens, 2005; 18(7): 930-934

Edwards DG, Mastin CR, Kenefick RW. Wave reflection and central aortic pressure are increased in response to static and dynamic muscle contraction at comparable workloads. J Appl Physiol, 2008; 104: 439-445

Eller NH. Total power and high frequency components of heart rate variability and risk factors for atherosclerosis. Auton Neurosci Basic Clin, 2007; 131(1-2): 123-130

Fahs CA, Heffernan KS, Ranadive S, Jae SY, Fernhall B. Muscular strength is inversely associated with aortic stiffness in young men. Med Sci Sports Exerc, 2010; 42(9): 1619-1624

Hart EC, Charkoudian N, Joyner MJ, Barnes JN, Curry TB, Casey DP. Relationship between sympathetic nerve activity and aortic wave reflection characteristics in postmenopausal women. Menopause, 2013; 20(9): 960-966

Heffernan KS, Collier SR, Kelly EE, Jae SY, Fernhall B. Arterial stiffness and baroreflex sensitivity following bouts of aerobic and resistance exercise. Int. J. Sports Med, 2007; 28(3): 197-203

Hou J, Xiang C, Qin KR. Exercise controls arterial stiffness via hemodynamic modulation. IEEE Int Conf Control Autom ICCA, 947-951; 2013

Inbar O, Bar-Or O, Skinner JS. The Wingate Anaerobic Test. Champaign IL: Human Kinetics, 1-40; 1996

Kasikcioglu E, Oflaz H, Akhan H, Kayserilioglu A, Mercanoglu F, Umman B, Bugra Z. Left ventricular remodeling and aortic distensibility in elite power athletes. Heart Vessels, 2004; 19(4): 183-188

Kawano H, Tanaka H, Miyachi M. Resistance training and arterial compliance: keeping the benefits while minimizing the stiffening. J Hypertens, 2006; 24(9): 1753-1759

Kingwell BA, Waddell TK, Medley TL, Cameron JD, Dart AM. Large artery stiffness predicts ischemic threshold in patients with coronary artery disease. J Am Coll Cardiol, 2002; 40(4): 773-779

Maeda S, Otsuki T, Iemitsu M, Kamioka M, Sugawara J, Kuno S, Ajisaka R, Tanaka H. ffects of leg resistance training on arterial function in older men. Br J Sports Med, 2006; 40(10): 867-869

Michelini LC, Stern JE. Exercise-induced neuronal plasticity in central autonomic networks: Role in cardiovascular control. Exp Physiol, 2009; 94(9): 947-9460

Mitchell GF, Van Buchem MA, Sigurdsson S, Gotal JD, Jonsdottir MK, Kjartansson Ó, Garcia M, Aspelund T, Harris TB, Gudnason V, Launer LJ. Arterial stiffness, pressure and flow pulsatility and brain structure and function: The Age, Gene/Environment Susceptibility-Reykjavik Study. Brain, 2011; 134(11): 33983407

Miyachi M, Donato AJ, Yamamoto K, Takahashi K, Gates PE, Moreau KL, Tanaka H. Greater age-related reductions in central arterial compliance in resistance-trained men. Hypertension, 2003; 41(1): 130-135

Müller J, Wilms M, Oberhoffer R. Acute effects of submaximal endurance training on arterial stiffness in healthy middle- and long-distance runners. J Clin Hypertens, 2015; 17(5): 371-374

Okamoto T, Masuhara M. Combined aerobic and resistance training and vascular function: effect of aerobic exercise before and after resistance training. J Appl Physiol, 2007; 103: 1655-1661

Okamoto T, Masuhara M, Ikuta K. Upper but not lower limb resistance training increases arterial stiffness in humans. Eur J Appl Physiol, 2009; 107(2): 127-134

Oliver JJ, Webb DJ. Noninvasive assessment of arterial stiffness and risk of atherosclerotic events. Arterioscler Thromb Vasc Biol, 2003; 23(4): 554-566 
Raastad T, Glomsheller T, Bjøro T, Hallén J. Changes in human skeletal muscle contractility and hormone status during 2 weeks of heavy strength training. Eur J Appl Physiol, 2001; 84(1-2): 54-63

Rakobowchuk M, Stuckey MI, Millar PJ, Gurr L, MacDonald MJ. Effect of acute sprint interval exercise on central and peripheral artery distensibility in young healthy males. Eur J Appl Physiol, 2009; 105(5): 787795

Rossow L, Fahs CA, Guerra M, Jae SY, Heffernan KS, Fernhall B. Acute effects of supramaximal exercise on carotid artery compliance and pulse pressure in young men and women. Eur J Appl Physiol, 2010; 110(4): 729-737

Rowell LB, Brengelmann GL, Blackmon JR, Bruge RA, Murray JA. Disparities between aortic and peripheral pulse pressures induced by upright exercise and vasovotor changes in man. Circulation, 1968; 37(6): 954964

Sagiv M, Ben-Sira D, Goldhammer E. Direct vs. indirect blood pressure measurement at peak anaerobic exercise. Int. J. Sports Med, 1999; 20(5): 275-278

Schmidt-Trucksass A, Schmid A, Brunner C, Scherer N, Zach G, Keul J, Huonker M. Arterial properties of the carotid and femoral artery in endurance-trained and paraplegic subjects. J Appl Physiol, 2000; 89(5): 1956-1963

Sharman JE, McEniery CM, Campbell RI, Coombes JS, Wilkinson IB, Cockcroft JR. The effect of exercise on large artery haemodynamics in healthy young men. Eur J Clin Invest, 2005; 35(12): 738-744

Shim CY, Yang WI, Park S, Kang MK, Ko YG, Choi D, Jang Y, Chung N, Ha JW. Overweight and its association with aortic pressure wave reflection after exercise. Am J Hypertens, 2011; 24(10): 1136-1142

Smith MM, Minson CT. Obesity and adipokines: Effects on sympathetic overactivity. J Physiol, 2012; 590(8): 1787-801

Stuckey MI, Tordi N, Mourot L, Gurr LJ, Rakobowchuk M, Millar PJ, Toth R, MacDonald MJ, Kamath MV. Autonomic recovery following sprint interval exercise. Scand J Med Sci Sport, 2012; 22(6): 756-763

Thiebaud RS, Fahs CA, Rossow LM, Loenneke JP, Kim D, Mouser JG, Beck TW, Bemben DA, Larson RD, Bemben MG. Effects of age on arterial stiffness and central blood pressure after an acute bout of resistance exercise. Eur J Appl Physiol, 2016; 116(1): 39-48

Tordi N, Mourot L, Colin E, Regnard J. Intermittent versus constant aerobic exercise: Effects on arterial stiffness. Eur J Appl Physiol, 2010; 108(4): 801-809

White DW, Raven PB. Autonomic neural control of heart rate during dynamic exercise: revisited. J Physiol, 2014; 592(12): 2491-2500

Yan H, Ranadive SM, Heffernan KS, Lane AD, Kappus RM, Cook MD, Wu PT, Sun P, Harvey IS, Woods JA, Wilund, KR, Fernhall B. Hemodynamic and arterial stiffness differences between African-Americans and Caucasians after maximal exercise. AJP Hear Circ Physiol, 2014; 306(1): 60-68

Yoon ES, Jung SJ, Cheun SK, Oh YS, Kim SH, Jae SY. Effects of acute resistance exercise on arterial stiffness in young men. Korean Circ J, 2010; 40(1): 16-22

\section{Corresponding author:}

\section{Okkes Alpaslan Gencay}

Address: School of Physical Education and Sports Kahramanmaras Sutcu Imam University, Avsar Yerleskesi, Onikisubat, Kahramanmaras, Turkey

Tel: +90 (344) 3002195

Fax: +90 (344) 3002191

E-mail: agencay@gmail.com 